\title{
THE BACKLOG: BARBARA'S ACHILLES HEEL?
}

\author{
Howard Adelman
}

Barbara McDougall, our Minister of Employment and Immigration, has managed a brilliant balancing act. She has raised the immigration plan to 250,000 per year without arousing a massive backlash. She has refused to introduce the draconian and unworkable provision for turning back refugee claimants arriving from countries where they sojourned for more than $\mathbf{4 8}$ hours and where they theoretically could have made a refugee claim. The new refugee determination system is sputtering along in spite of the slow pace of reform, many inexperienced refugee lawyers and the large number of claimants.

Is Barbara's Achilles heel the backlog, those refugee claims dating back two and more years prior to the introduction of the new system? The Interchurch Committee claimed, in its brief to the United Nations Committee on Human Rights, that there are 101,853 cases in the backlog and 122,223 affected individuals, though the department operates on the assumption, for planning purposes, that there are still only 85,000 cases because that is the number for which the department was funded. The irony may be that, in fact, the latter is close to the correct figure because of poor departmental record keeping - double counting, including old files in the estimates, etc. We will use the estimate of 85,000 cases.

On December 28, 1988, Barbara announced that she was launching a two year plan to clear up the refugee claims backlog through a case-by-case hearing system to determine which claimants were credible or had humanitarian and compassionate grounds to be allowed to remain. The backlog was supposed to have been cleared up by the end of December 1990. As of the end of October 1990, there are still 58,432 undecided cases. By September of 1991, the revised deadline for clearing up the backlog, will the task be done?

To the end of October 31, 1990, only 167 individuals have actually been deported. The reason that only 167 of 1,121 cases have been deported is a comment on the complicated bureaucracy needed to remove people from Canada. Only 595 of the 1,121 cases that received negative decisions have received their removal order; 526 are pending. Of the 595, 315 are waiting for a review, and only 280 cases have been ordered deported. Between that order and making the actual arrangements visas, transport, escorts, etc. - there are additional delays. The costs of deporting each individual is, therefore, very high. The cost of clearing up the backlog in two years was estimated at just over $\$ 114$, 000,000 . Add to that the estimated costs of actual deportation not included in this figure of $\$ 3,200$ per deportee on average. The deportation total is projected to reach 217 by the end of the year. Using the costs for processing only, the expenses for deportation to the end of 1990 will be $\$ 114,201,000+(217 \times \$ 3,200)$ $=$ approx. $\$ 115,000,000$, over one half million dollars per deportee. Even if the 2,936 confirmed voluntary departures are thrown into the total, an estimated 3,246 by the end of 1990 , the cost is about $\$ 33,000$ per case.

A Parliamentary Committee estimated that the clearance, at the rate then being processed, would take over 6 years at a processing rate of 13,000 cases per year at full strength, and could cost over half a billion dollars, almost as much as the UNHCR receives in a year to support 15 million refugees around the world.

The speeded up paper processing started in the summer of 1990 will undoubtedly reduce the period to clear the backlog, but will it enable the September 1991 revised target to come close to being met? Before we look at the actual figures processed in the last two months, it is important to understand that the backlog cases are being handled

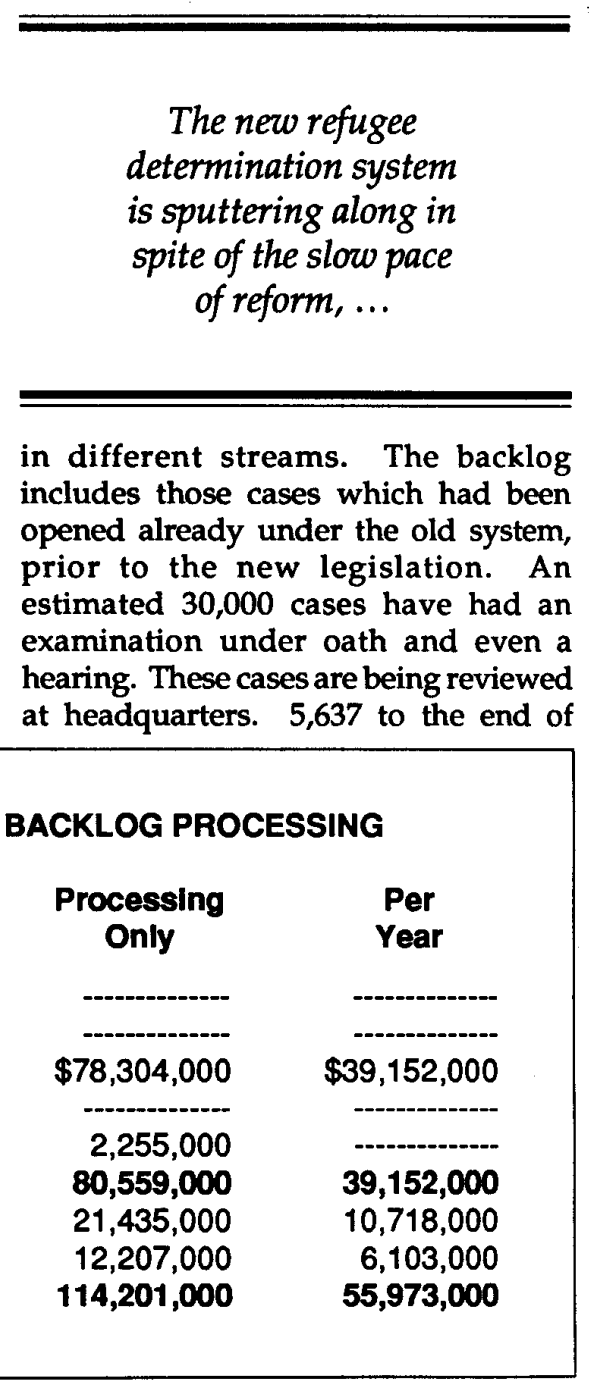

\section{ESTIMATED COST OF BACKLOG PROCESSING}

\begin{tabular}{|c|c|c|c|}
\hline & $\begin{array}{c}\text { Total } \\
\text { Program }\end{array}$ & $\begin{array}{l}\text { Processing } \\
\text { Only }\end{array}$ & $\begin{array}{l}\text { Per } \\
\text { Year }\end{array}$ \\
\hline Accommodation & $\$ 10,471,000$ & ------------- & \\
\hline Language Training & $45,900,000$ & --.-----.---- & \\
\hline Operations & $78,304,000$ & $\$ 78,304,000$ & $\$ 39,152,000$ \\
\hline Settlement & $11,251,000$ & --_------ & - \\
\hline Start-up & $2,255,000$ & $2,255,000$ & -----------.. \\
\hline Subtotal & $148,181,000$ & $80,559,000$ & $39,152,000$ \\
\hline Immigration & $21,435,000$ & $21,435,000$ & $10,718,000$ \\
\hline IRB & $12,207,000$ & $12,207,000$ & $6,103,000$ \\
\hline Total & $181,823,000$ & $114,201,000$ & $55,973,000$ \\
\hline
\end{tabular}


October have been determined to have passed the credible basis test and have been given landed status. Of the balance that have gone to a hearing and been decided, 1815 have been accepted, 680 have been rejected and the rest are waiting for a determination of their cases. In other words, for $30 \%$ of the total case load ( 30,000 of 85,000 cases), $30 \%$ of the cases have been processed to the end of October $(8,132$ of 26,568$)$ by means of a paper review. This does not auger well for the promise that the cases will all have been processed by September of 1991.

There is another peculiarity when we examine the figures from this oldest set of cases. They constitute $30 \%$ of the total case load. But they contain $37.5 \%$ of those accepted $(5,637+1,815$ of 19,845$)$ and a startling $60 \%$ of those rejected, which initially seems surprising since most of the 30,000 were believed to come from refugee producing countries. But all it means is that of the balance of the other cases, a much higher proportion have agreed to leave Canada voluntarily.

Of the balance of the 55,000 "new" cases, the vast majority of the files have not been opened. Those claimants are being asked to fill out long questionnaires for a paper process. In Montreal, by the end of December, kits will have been sent to every claimant to complete the new forms and all the files are expected to be opened. In Toronto and Mississauga, with well over $50 \%$ of the case load, all the files will not be opened by the end of December, but all are expected to receive them by the spring of 1991. The claimants will have 6-8 weeks to complete the questionnaires and department officials estimate that it will take another 2 - 3 months to provide a paper review of the cases. The claimants are subdivided into two streams, those the department intends to

$$
\begin{gathered}
\text { But the most startling } \\
\text { figure is the large numbers } \\
\text { going underground. } 33 \% \\
\text { to } 50 \% \text { are not leaving } \\
\text { anyway and those } \\
\text { proportions are increasing } \\
\text { dramatically }
\end{gathered}
$$

concede and those who will be given a hearing - those cases which the department intends to contest. The critical issue is not how many files are opened, but how many will be processed under the speeded up paper review. Since the paper review was only initiated in the summer, we cannot expect any results until the beginning of 1991 so we have no way of knowing whether the speeded up paper process will enable the job to be completed by September.

Nevertheless, a close examination of the statistics to date are very revealing. The actual number of cases being processed has increased, but not significantly. At the October rate, it will still take almost three more years to clear the backlog. However, if the paper processing works as planned, and one has every reason to be sceptical about this, the real problem in the system may be elsewhere. Of the total number of cases, extrapolating from the present, the whole process will result in at most 3,700 negative decisions. Adding voluntary departures will add at most another 7,700 cases. In other words, to get rid of at most 11,000 cases, $13 \%$ of the total, we are going to spend $\$ 170,000,000$ in processing costs and a further estimated $\$ 30,000,000$ in direct deportation charges, or about $\$ 40,000$ per each person deported. If the voluntary departures are factored in, the cost for every individual made to leave is almost $\$ 15,000$ per case. All this assumes that the program can be completed by the end of 1991 and, if it cannot, the costs go up proportionately.

But the most startling figure is the large numbers going underground. $33 \%$

\begin{tabular}{|c|c|c|c|c|c|c|c|}
\hline TO DATE & $\begin{array}{l}\text { Sept. } \\
1990\end{array}$ & $\begin{array}{r}\text { Oct. } \\
1990\end{array}$ & $\begin{array}{r}\text { Month } \\
\text { Incr. }\end{array}$ & $\begin{array}{r}\text { To End } \\
1990\end{array}$ & $\begin{array}{l}\text { Total } \\
1991\end{array}$ & Balance & $\begin{array}{r}\text { Projected } \\
\text { on } \\
\text { Oct. } 1990\end{array}$ \\
\hline Opened & 42,667 & 45,516 & 2,949 & 51,414 & $\mathbf{n} / \mathbf{a}$ & 33,586 & 33,586 \\
\hline Decided & 24,364 & 26,568 & 2,204 & 30,976 & 26,448 & 54,024 & 54,024 \\
\hline Accepted & 18,728 & 19,845 & 1,117 & 22,079 & 13,404 & 38,507 & 27,380 \\
\hline Balance & 5,536 & 6,723 & 1,087 & 8,897 & 13,044 & 15,517 & 26,644 \\
\hline \multicolumn{8}{|l|}{ Non-Accepted } \\
\hline Negative & 969 & 1,121 & 152 & 1,425 & 1,824 & 2,485 & 3,726 \\
\hline Vol. Dep. & 3,869 & 4,066 & 197 & 4,460 & 2,364 & 7,779 & 4,829 \\
\hline Warrants/Disapp. & 798 & 1,536 & 738 & 3,012 & 8,856 & 5,253 & 18,089 \\
\hline Total & 24,364 & 26,568 & 2,204 & 30,976 & 26,448 & 54,024 & 54,024 \\
\hline Deported & 142 & 167 & 25 & 217 & 300 & & \\
\hline Departed & 2,781 & 2,936 & 155 & 3,246 & 1,860 & & \\
\hline
\end{tabular}
to $50 \%$ are not leaving anyway and those proportions are increasing dramatically. The explanation for the dramatic rise in this figure may be found by looking more closely at the voluntary

\section{BACKLOG STATISTICS - OCTOBER 1990}


departure figure. Of the 2936 confirmed departures to the end of October, 1750 of them were Portuguese, $60 \%$ of the total. There were 4,066 in the backlog and that large a number were unable to obtain bookings back to Portugal in the busy travel period. When the Portuguese who are voluntarily leaving have all returned to Portugal, the proportions of voluntary departures can be expected to drop dramatically and the numbers that will go underground can be expected to increase beyond the proportions and numbers projected. We can anticipate a class of at least 18,000 illegals living underground.

Is the process worth it? I originally supported Barbara's attempt to balance humanitarian concerns, authentic refugee determination and deterrence for clearly abusive cases. I thought a liberal and speedy process for adjudicating the refugee claims in the backlog tempered by a humanitarian concern for some of the others and deportation for abusers without humanitarian mitigating factors would set a proper balance. Whether or not I was wrong at the time, is it correct to continue such support under the present circumstances?

There is a campaign being organized at the present time by the refugee support community for an amnesty. Clearly, these groups are not supporters of those who abuse the refugee system to jump from the immigration queue. It jeopardizes the refugee system and creates extra work for them. Is the call for an amnesty warranted?

Why have they urged an amnesty? Because the system is inhumane. Because in the defense of the rule of law, the law is being abused. Because rather than deterring future abusers, the method of dealing with the backlog is setting the stage for future abuse.

It is not necessary to go into the history of the backlog, but it does help to know that the amnesty introduced to be the last one ever was done so before a new system was in place to deter new abusers. In fact Bill C- 55 was not even tabled until 8 months after the amnesty. At the time there was widespread suspicion that the flood of abusers who took advantage of the window of opportunity were part of the dramatic scare tactics to drum up public support for Bill C-55, particularly the draconian measure of the safe third country option which would have prevented most legitimate refugee claimants from ever having the opportunity to make a refugee claim in Canada. In any case, the situation is dramatically different at the present time. A new system is in place. It is not being abused by a flood of manifestly unfounded claims. The suffering the individuals have endured in the backlog is more than enough to have deterred abusers in the future.

The arguments for those urging amnesty can be summarized easily.

If, in order to deal with abusers,

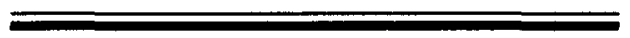

\section{An Ontario court has}

ruled that justice delayed

more than 18 months is

unjust. In the case of the

backlog, the justice delayed

for many in the system has

been three, four and five

years.

genuine refugees are made to suffer further misery by being pushed to the back of the line, the cost is much too high. If, in order to uphold the abstract rule of law, we break our own laws in the process, the cost is much too high. If we rewrite history and blame the previous amnesty for the subsequent abuse, the cost is much too high. If after years and years in the backlog, it takes another year for a claimant to get landed and at least a further year to be reunited with their immediate families, disregarding for the moment the risk to torture and abuse of the relatives of genuine refugee claimants in the backlog, the cost to that family is much too high. When the dedicated and underpaid workers in our ISAP agencies who deliver immigrant aid services to immigrants and refugees have their work loads clogged up with those in the backlog, the costs are much too high.
Are these arguments convincing?

It is fair to say that Barbara is, I believe, genuinely concerned with separating out fair treatment for genuine refugee claimants while providing strong deterrence for abusers. Barbara is certainly concerned with upholding the rule of law and seeing that abusers are not rewarded for jumping the queue. Barbara does not want to set a precedent with another amnesty which might encourage future abuse.

But is this the way to go about it? Judge Jerome had to rule that the system violated our own law demanding humanitarian treatment. The system has not developed a common standard of treatment. It is beset by arbitrariness and the requirement that humanitarian considerations govern the process. No one who is at all acquainted with the degree of suffering of those in the backlog can make any claim for humanitarian consideration. The suffering has now been documented, not only by the Interchurch Committee in Toronto, which can be accused of having its own bleeding heart to mollify, but by an independent research institute at the Université de Quebec, Le Laboratoire de Recherche en Ecologie Humaine et Sociale (Le LAREHS). The depression, anxiety, loneliness, sleeplessness, nightmares and psychosomatic symptoms that pervade not only the abusers but the genuine refugee claimants waiting years in the backlog stream can justly be labelled cruel and inhuman punishment for those who abused the system and totally unwarranted for those trapped by our own mistakes.

An Ontario court has ruled that justice delayed more than 18 months is unjust. In the case of the backlog, the justice delayed for many in the system has been three, four and five years. The United Nations Committee for Human Rights could rule that Canada, a leader in the defence of human rights, has indeed abused the rights of those in the backlog according to Article 2 requiring effective remedies for abuse, Article 7 which prohibits cruel and inhuman treatment, Article 23 demanding protection of the family and Article 26 demanding equal 
treatment before the law in accordance with the International Covenant on Civil and Political Rights.

The government held its nose when 13,000 Poles used the opportunity of the self-exiled class provisions (before that class was eliminated) to enter Canada as refugees when Poland was no longer, and had not been for some time, a refugee producing country. We allowed them to "abuse" the principle of the system if not

\section{Now is the time to reverse ourselves before we dig ourselves in deeper.}

the law. We cannot claim purity in either our motives, procedures or conduct to justify standing on the high horse of principle and, at the same time, perpetuating unnecessary suffering. And the costs of upholding principles which are already seriously compromised are enormous. If we add to these factors the very high cost for each case actually deported, the very high numbers that will enter the illegal underground in Canada and the very doubtful projection that the process can ever be completed by the end of 1991 , it is very difficult to continue supporting the present system. However, if an amnesty is offered now, there is a further complication. Some will have been deported while if you got into the stream much later, you will have earned an amnesty. It just would not be fair.

But only 167 have been deported to the end of October and about 200 cases will only have been deported by the end of 1990. Now is the time to reverse ourselves before we dig ourselves in deeper. I now urge the Tory government and Barbara to change the stubborn defence of the present method of dealing with the backlog. $\mathrm{B}$

(Howard Adelman is a Professor of Philosophy at York University and directs the Centre for Refugee Studies, a research centrefocused on refugees which was recently recognized by the Government of Canada as a Centre of Excellence.)

\title{
IF YOU LOVE, THEN HAVE COMPASSION...
}

\author{
Fr. Olivier Morin SJ, \\ Jesuit Refugee Service, Toronto
}

For four and a half years I have been serving Vietnamese refugees in the camp in Southeast Asia: a year on Pulau Bidong, in Malaysia, and three and a half years at Phanat Nikhom in Thailand. During this period, the situation has changed in the camps, principally because of the decision taken that Vietnamese who have arrived after 14th March, 1989, will not be recognized as "refugees", but will only be known as "asylum seekers".

Whatever my own opinion about the moral and humanitarian value of such a decision, I am forced to accept it as a fact and to assess the consequences. Nothing can allow us to think seriously that this decision will be reconsidered. On the contrary new events, such as the significant migration from East Europe, for example, can but reinforce it.

From this decision several consequences have followed:

1. A very small number of asylum seekers (between $10 \%$ and $16 \%$ ), who have documentation proving they have suffered persecution or that their lives were threatened, have been recognized by the ad hoc commission (they are 'screened in') and can seek to be accepted in a third country. Minors who have their father or mother in a third country may be screened in, but a sponsorship by a brother, uncle or friend helps no one.

2. The great majority do not possess such documents or cannot substantiate their claims and so are rejected ('screened out').

a) From the moment of arrival in the camp, some know very well that they have no chance, and rather than wait long months in difficult conditions they prefer to accept the evidence and request 'voluntary repatriation'. But they must present themselves to a Vietnamese government delegation, and this is an obstacle that diminishes their desire to return to Vietnam. What are the guarantees? Even the UNHCR is vague on this point.

b) Some, hoping against all hope, want to try their luck and wait their turn to be screened. This is a very slowprocess. The recent arrivals will wait one or even two years if nothing is done to speed up the pace. They can also appeal against an unfavourabledecision, but the results are negligible. After all this they will still be in a hopeless situation and caught in the severity of camp life.

c) Finally, there is a group who do not actually request voluntary repatriation, but who have not formally opposed a return, so the first asylum country decides to send them back. This group is not normally required to go before the Vietnamese delegation. They may feel unlucky, but they do not lose face. They are something like those who missed the boat before it left the beach.

Having lived at Phanat Nikhom and followed this matter quite closely my personal convictions are as follows:

- Nothing, absolutely nothing can persuade me that the date limit of 14 March, 1989, will be lifted. So our responsibility is considerable, and what possible considerations are there that can allow us to say: "maintain your refusal". We are playing with human lives if we insist on such a position. It would be wrong for us to propose our wishes (which are easy to voice from the freedom of our new countries), if they conflict with the reality.

- In such a situation we have no right to encourage false hopes. The truth, however painful it may be, must be spoken, otherwise we are responsible for the (possible) desperate actions that asylum seekers take when they have been misled even by those who wish to help them.

- The approach mentioned in (c), above, may offer one possible way forward, particularly if we can offer some solidarity to those sent back. It avoids the humiliation of having to publicly admit to failure. Another problem is that in order to leave, the Vietnamese have sold everything, thus their return is made even more difficult 